\title{
Community assemblage of free-living diazotrophs along the elevational gradient of Mount Gongga
}

\author{
Yansu Wang1, Chaonan $\mathrm{Li}^{2}$, Zehao Shen ${ }^{3}$, Junpeng Rui ${ }^{2}$, Decai Jin ${ }^{4}$, Jiabao $\mathrm{Li}^{2,{ }^{*}}$, Xiangzhen $\mathrm{Li}^{2,{ }^{*}}$ \\ 1 Key Laboratory of Biotechnology for Medicinal Plants of Jiangsu Province and School of Life Sciences, Jiangsu Normal University, \\ Xuzhou 221116, China \\ 2 Key Laboratory of Environmental and Applied Microbiology, CAS; Environmental Microbiology Key Laboratory of Sichuan Province, \\ Chengdu Institute of Biology, Chinese Academy of Sciences, Chengdu 610041, China \\ 3 Department of Ecology, Ministry of Education Key Laboratory for Earth Surface Processes, Peking University, Beijing 100871, China \\ 4 Key Laboratory of Environmental Biotechnology, Research Center for Eco-Environmental Sciences, Chinese Academy of Sciences, \\ Beijing 100085, China
}

\section{A R TICLE I N F O}

Article history:

Received August 30, 2018

Revised November 13, 2018

Accepted November 20, 2018

\section{Keywords:}

Diazotrophs

Community assemblage

Elevational gradient

Mount Gongga

\begin{abstract}
A B S TRACT
Mountain systems are unique for studying the responses of species distribution and diversity to environmental changes along elevational gradients. It is well known that free-living diazotrophic microorganisms are important to nitrogen cycling in mountain systems. However, the elevational patterns of free-living diazotrophs and the underlying ecological processes in controlling their turnover along broader gradients are less well documented. Here, we investigated the pattern of diazotrophic diversity along the elevational gradient (1800 m-4100 $\mathrm{m}$ ) in Mount Gongga of China. The results showed that the a-diversity of diazotrophs did not change with the elevation from $1800 \mathrm{~m}$ to $2800 \mathrm{~m}$, but decreased at elevations above $3000 \mathrm{~m}$. Such diversity pattern was driven mainly by soil total carbon, nitrogen, and plant richness. Various diazotrophic taxa showed differential abundance-elevation relationships. Ecological processes determining diazotrophic community assemblage shift along the elevations. Deterministic processes were relatively stronger at both low and high elevations, whereas stochastic processes were stronger at the middle elevation. This study also suggested a strong relationship among aboveground plants and diazotrophs, highlighting their potential interactions, even for free-living diazotrophs.
\end{abstract}

(c) Higher Education Press 2019

\section{Introduction}

Nitrogen $(\mathrm{N})$ limitations occur in most temperate, boreal forests and alpine tundra (Vitousek and Howarth, 1991; Rastetter et al., 2001; DeLuca et al., 2002; Thébault et al., 2014; Blaško et al., 2015). Biological nitrogen fixation is the

\footnotetext{
* Corresponding author

E-mail address: lijb@cib.ac.cn (J. Li); lixz@cib.ac.cn (X. Li)
}

primary process that contributes to the net nitrogen input in natural ecosystems, which is mediated by diazotrophic communities. The nifH gene, encoding the reductase subunit of nitrogenase, is often used to characterize diazotrophs (Zehr et al., 2003). Diazotrophs are either free-living or symbiotically associated with plants. Intensive studies have been conducted on symbiotic diazotrophs, while more and more studies have revealed the importance of free-living diazotrophs to N inputs in natural ecosystems (Reed et al., 2011; Reed et al., 2013; Wang et al., 2017a).

Mountains are unique systems for studying how microbial 
communities respond to continuous changes in climate, soil, and vegetation, and to predict the consequences of the species distribution and diversity pattern under future climatic scenarios (Elsen and Tingley, 2015). Various elevational diversity patterns have been observed for trees, mammals, birds, insects, and microbes, including a pattern of monotonically decreasing diversity with increasing elevation, a unimodal pattern with a peak at mid-elevations, and nonsignificant elevational patterns (Rahbek, 1995; McCain, 2005; Wu et al., 2013a; Shen et al., 2014; Smith et al., 2014; Rowe et al., 2015; Sproull et al., 2015). Bryant et al. (2008) show that bacterial taxon richness and phylogenetic diversity decrease monotonically from the lowest to highest elevations, while Shen et al. (2013) show that soil bacterial diversity, mainly driven by soil $\mathrm{pH}$, exhibits neither a monotonous nor unimodal diversity pattern within the elevational gradient on Changbai Mountain. Thus, it is necessary to elucidate the underlying ecological mechanisms shaping microbial diversity patterns, especially for subcommunities, such as diazotrophs. Additionally, previous researches demonstrate that variations in the diazotrophic community structure are strongly associated with temperature, rainfall, plant species, and soil $\mathrm{pH}$ (Collavino et al., 2014; Desgarennes et al., 2014; Santos et al., 2014; Rui et al., 2015). However, the abiotic and biotic processes that shape the elevational patterns of diazotrophs are still indefinable.

Niche-based theory and neutral theory are documented to explain the underlying ecological processes shaping diversity patterns (Leibold and McPeek, 2006; Dumbrell et al., 2010). Niche-based theory assumes that species assemblages are driven by deterministic factors, while neutral theory hypothesizes that stochastic processes play key roles. Deterministic drivers can be viewed as environmental filters for interspecific interactions (e.g., competition, predation). Stochastic drivers of diversity include ecological drift, birth, death, colonization, speciation, and extinction (Tilman, 2004; Chase and Myers, 2011). The relative importance of deterministic and stochastic processes in mediating microbial community assemblages may be promoted or restrained by environmental changes (Chase, 2007a; Zhou et al., 2014; Zhang et al., 2016). The elevation-related shifts of these two processes in a mountain system are expected; however, the relative contributions of these processes to the assemblage of diazotrophic communities along the elevational gradients are less understood.

Mount Gongga is located at the south-eastern fringe of the Tibetan Plateau with its highest peak of $7556 \mathrm{~m}$ above sea level (a.s.I.) (Wang et al., 2005). Many studies have been conducted on the diversity patterns of plant, animal, bacterial, and fungal communities in Mount Gongga (Shen et al., 2001; Wu et al., 2013b; Sun et al., 2016; Tian et al., 2017; Li et al., 2018). However, the elevational changes of soil free-living diazotrophs still need to be ascertained. This study aimed to investigate: (1) soil diazotrophic diversity patterns along the elevational gradient of Mount Gongga (1800 to 4100 m a.s.I.); (2) the main driving forces shaping diversity patterns along the elevational gradient; and (3) the relative contributions of deterministic and stochastic processes in controlling diazotrophic communities.

\section{Materials and methods}

\subsection{Study site descriptions}

Sampling sites are located at the eastern slope of Mount Gongga $\left(29^{\circ} 01^{\prime} \mathrm{N}-30^{\circ} 05^{\prime} \mathrm{N}, 101^{\circ} 29^{\prime} \mathrm{E}-102^{\circ} 12^{\prime} \mathrm{E}\right)$, which is the transitional area to the humid Sichuan basin. The elevation in our study area ranges from 1800 to $4100 \mathrm{~m}$ a.s.l. Climate is influenced by the south-eastern Pacific monsoon. The mean annual precipitation is 1158.46 to $2661.71 \mathrm{~mm}$ and the annual mean temperature is $-2.68^{\circ} \mathrm{C}$ to $11.20^{\circ} \mathrm{C}$. Great elevational changes within a short distance result in diverse vegetation types from the subtropical to the alpine cold vegetation ( $\mathrm{Lu}$ and Cheng, 2009). The vertical vegetation zones include the evergreen or deciduous broad-leaved forest (EDBF; 1800$2500 \mathrm{~m}$ a.s.I.), conifer and broad-leaved mixed forest (CBMF; 2500-2850 m a.s.I.), dark conifer forest (DCF; 2850-3600 m a.s.I.), and alpine shrub and meadow (ASM; 3600-4100 m a.s.l.). The main soil types include brown soil (1800-2500 m a.s.I.), dark brown soil (2500-2850 m a.s.I.), brown coniferous forest soils (2850-3600 m a.s.I.), and dark felty soils (3600$4100 \mathrm{~m}$ a.s.I.) (Cheng and Luo, 2003; Li et al., 2013). The detailed information is shown in Table S1 and Fig. S1.

\subsection{Soil sampling, soil and plant property measurements}

We collected 84 soil samples from 12 sites along the east slope of Mount Gongga in October 2014 at the elevation ranges from 1800 to $4100 \mathrm{~m}$ with about $200 \mathrm{~m}$ intervals between adjacent sites, including $1800 \mathrm{~m}$ a.s.l., $2000 \mathrm{~m}$ a.s.l., $2200 \mathrm{~m}$ a.s.I., $2400 \mathrm{~m}$ a.s.l., $2600 \mathrm{~m}$ a.s.l., $2800 \mathrm{~m}$ a.s.I., 3000 $\mathrm{m}$ a.s.l., $3200 \mathrm{~m}$ a.s.l., $3600 \mathrm{~m}$ a.s.l., $3800 \mathrm{~m}$ a.s.l., $4000 \mathrm{~m}$ a.s.l., and $4100 \mathrm{~m}$ a.s.l. At each sampling site, five to eight plots $(10 \times 10 \mathrm{~m}$ for each plot, $>50 \mathrm{~m}$ apart between plots) were established. In each plot, five soil cores (0-10 cm depth after removing litter layer) were collected and pooled as a plot sample.

After gentle homogenization and removal of roots and stones in the laboratory, the moist soil was divided into two parts. One part of soil was filtered through a $2 \mathrm{~mm}$ sieve after being air-dried and stored at $4^{\circ} \mathrm{C}$ for soil physiochemical property measurements. The other part was freeze-dried and stored at $-20^{\circ} \mathrm{C}$ for DNA extraction. The soil $\mathrm{pH}$ and conductivity were determined in a soil and water suspension with a soil:water ratio of $1: 5$ using a $\mathrm{pH}$ and conductivity meter. Total carbon (TC) and total nitrogen (TN) were determined using an elemental analyzer (Vario Macro Cube, Germany). The $\mathrm{NH}_{4}{ }^{+}-\mathrm{N}$ and $\mathrm{NO}_{3}{ }^{-}-\mathrm{N}$ were measured by the indophenol blue and the phenol disulfonic acid methods, respectively (Doane and Horwáth, 2003; Weatherburn, 1967).

Mean annual precipitation (MAP) and mean annual 
temperature (MAT) were linearly calculated based on the recordings at the two meteorological stations (Hailuogou Station, $101^{\circ} 59^{\prime} 54^{\prime \prime} \mathrm{E}, 29^{\circ} 34^{\prime} 34^{\prime \prime} \mathrm{N}, 2947.8 \mathrm{~m}$ a.s.I., and Moxi Station, $102^{\circ} 06^{\prime} 55^{\prime \prime E}, 2^{\circ} 38^{\prime} 59^{\prime \prime} \mathrm{N}, 1621.7 \mathrm{~m}$ a.s.I.). Plant compositions were previously surveyed by Shen et al. (2001), and we used these data to calculate plant species richness. We calculated the normalized difference vegetation index (NDVI), a proxy of vegetation productivity, based on satellite remote sensing data. NDVI values have been produced from visible and near-infrared reflectance measurements: $N D V I=$ (NIR-VIS)/(NIR + VIS), where NIR represents near-infrared light reflected by the vegetation, and VIS represents the visible light reflected by the vegetation (Pettorelli et al., 2006; Piao et al., 2014). In our data, at high elevations, the negative NDVI values correspond to an absence of vegetation or snowcovered land.

\subsection{Amplification and sequence processing}

Soil genomic DNA was extracted using a PowerSoil ${ }^{\circ}$ DNA Isolation kit (MO BIO Laboratories, Inc., CA, USA). Primers PolF1 (5'-TGC GAI CCS AAI GCI GAC TC-3')/AQER (5'-GAC GAT GTA GAT YTC CTG-3') were used for the amplification of nifH genes tagged with a 12 bp barcode on AQER (Poly et al., 2001; Wartiainen et al., 2008). The $25 \mu \mathrm{L}$ PCR reaction system included $1 \mu \mathrm{L}$ of each $10 \mu \mathrm{M}$ primer, $20 \mathrm{ng}$ of template DNA, and $12.5 \mu \mathrm{L}$ of MasterMix containing Taq DNA Polymerase, PCR Buffer, $\mathrm{Mg}^{2+}$ and dNTPs (CWBIO, China). The PCR mixture was subjected to initial denaturation at $95^{\circ} \mathrm{C}$ for $3 \mathrm{~min}$, followed by 35 cycles of $94^{\circ} \mathrm{C}$ for $1 \mathrm{~min}, 54^{\circ} \mathrm{C}$ for 1 $\min , 72^{\circ} \mathrm{C}$ for $1 \mathrm{~min}$, and a final extension at $72^{\circ} \mathrm{C}$ for $10 \mathrm{~min}$. PCR products were sequenced using an Illumina Miseq sequencer at Chengdu Institute of Biology, CAS, China. Raw sequence data obtained in this study were deposited in the European Nucleotide Archive under accession No. PRJEB22983 (http://www.ebi.ac.uk/ena/data/view/ PRJEB22983).

Sequence analyses were processed through the QIIME pipeline (http://bio.cug.edu.cn/qiime/). A unique barcodetagged primer was used to assign sequences to each sample. Sequence quality was checked and the low-quality sequences were removed. Chimera sequences were removed using Usearch 8.0 in de novo mode. Sequences were assembled into Operational Taxonomic Units (OTUs) based on $96 \%$ pairwise similarity using UCLUST (Farnelid et al., 2013). Representative sequences were generated within each cluster. We downloaded nifH gene sequences of annotated diazotrophic taxa from the NCBI database and established an nifH gene reference database for taxonomic annotation (the database is available upon request). The BLASTn program was used for sequence alignment and OTU annotation at an $80 \%$ cutoff with the known taxonomic information. To summarize the results from BLASTn, the MEGAN program was used to compute and explore the taxonomical content according to the lowest common ancestor algorithm (Huson et al., 2007).

\subsection{Null model analysis}

$\beta$-diversity represents the compositional variation of species from site to site. The null modeling approach based on $\beta$ diversity provides a straightforward way to obtain insight on possible community assembly mechanisms (Myers et al., 2013). The Jaccard and Bray-Curtis similarities (in supplementary information) were used in this study. The observed similarity $\left(\mathrm{J}_{\mathrm{obs}}\right)$ and average expected similarity $\left(\overline{\mathrm{J}}_{\text {exp }}\right)$ of 999 iterations were obtained through the null model analysis. The standard effect size (SES) is calculated as: SES $=\left(\mathrm{J}_{\mathrm{obs}}-\overline{\mathrm{J}}_{\text {exp }}\right) /$ $S D_{\text {exp }}$, where $S D_{\text {exp }}$ represents the standard deviation of the 999 indices from the expected similarity $\left(\mathrm{J}_{\mathrm{exp}}\right)$. SES is an index to measure the influences of deterministic factors on community composition and abundance. The deterministic and stochastic processes may mediate the compositional variations interactively.

\subsection{Statistical analyses}

The Jaccard dissimilarity distance (1-Jaccard similarity) was calculated with the "vegdist" function in the $\mathrm{R}$ vegan package (Oksanen et al., 2007). Principal coordinate analysis (PCoA) was carried out by classical multidimensional scaling of the $\beta$ diversity distance using the "pcoa" function in $\mathrm{R}$ ape package (Gower, 1966; Paradis et al., 2004). The general differences in diazotrophic communities between samples or groups were tested by analyzing the dissimilarity (Adonis) (Clarke, 1993).

\section{Results}

\subsection{Diazotrophic compositions along the elevational gradient}

After quality trimming and chimera removal, 2036246 highquality sequences were retained from 4279595 raw sequences in 84 samples. Sequences were clustered into OTUs at a threshold of $96 \%$ similarity, and singleton OTUs were removed. The mean number of OTUs per sample was 204 to 755 . At the phylum level, $84.29 \%$ of the total sequences were classified, including Alphaproteobacteria (68.21\%), Betaproteobacteria (14.61\%), Gammaproteobacteria $(0.77 \%)$, Deltaproteobacteria $(0.69 \%)$, and Cyanobacterial Melainabacteria $(0.02 \%)$ (Fig. S2A). The average relative abundance of each phylum varied by elevation. For example, Alphaproteobacteria were negatively correlated with elevation; in contrast, Betaproteobacteria and Deltaproteobacteria were positively correlated with elevation (Fig. S3).

At the genus level, 21 genera (61.48\% of total sequences) were detected (Fig. S2B). Four top abundant genera were Bradyrhizobium, Sideroxydans, Polaromonas, and Beijerinckia. We used these four genera as examples to show the differential response patterns of specific taxa to elevation. The relative abundance of Beijerinckia did not show an obvious variation with elevation (Fig. 1A). The relative abundance of Bradyrhizobium significantly decreased with elevation, while Polaromonas increased with elevation (Fig. 1B and C). The 
relative abundance of Sideroxydans remained stable at a low elevation, and increased dramatically at elevations above $3000 \mathrm{~m}$ a.s.I. (Fig. 1D). Except for Beijerinckia, the other three genera were influenced significantly by various environmental factors (i.e., MAT, MAP, TN, TC) along the elevational gradient (Table S2).

\subsection{Elevation diversity patterns of the diazotrophic community}

The alpha diversity of diazotrophs showed a similar pattern along the elevational gradient indicated by various indices, including Chao1 (Chao, 1984), Shannon diversity index (Shannon et al., 1951), the observed species and Simpson index (Simpson, 1949). The alpha diversity maintained stability at low to middle elevations, and declined rapidly at elevations above $3000 \mathrm{~m}$ a.s.l. (Fig. 2). Plant richness showed a decreasing trend from low to high elevations and had a positive correlation to diazotrophic alpha diversity (Tables 1 and S3, $P<0.001$ ). Furthermore, plant productivity (NDVI) had a similar trend to the alpha diversity (Fig. 2 and Fig. S1). Because of collinear relationships between elevation and climate factors (Table S4), the alpha diversity indices had obvious correlations with MAT and MAP $(P<0.05$; Spearman's rho) (Table 1). Notably, within measured soil factors, soil total carbon (TC) and total nitrogen (TN) showed the highest correlations with alpha diversity. Other soil para- meters, such as soil $\mathrm{pH}$, conductivity, $\mathrm{NH}_{4}{ }^{+}-\mathrm{N}$, and $\mathrm{NO}_{3}{ }^{-}-\mathrm{N}$ also significantly correlated to the alpha diversity indices (Table. 1 and S3, $P<0.05$ ).

Unconstrained principal coordinate analysis (PCoA) revealed significant community structure variations with the elevation (Fig. S4 and Tables S5 and 6, $P<0.05$ ). Remarkably, plant richness had the highest Spearman coefficient with the Jaccard dissimilarity index and significantly influenced the assembly of diazotrophs indicated by the Mantel test (Table1 and Fig. 3; $R=0.60, P=0.001$ ). The shift of diazotrophs was also associated with climate changes caused by the elevational gradient. Within the soil variables examined, soil $\mathrm{pH}$ was the strongest factor influencing the diazotrophic assemblage along the elevational gradient (Table 1 and Fig. 3; $R=0.46, P$ $=0.001)$. The environmental driving factors showed similar correlations to diazotrophic communities when Bray-Curtis distance was used for the analysis above (Table S7).

\subsection{Ecological processes on diazotrophic community assemblages along the elevational gradient}

Deterministic selections and stochastic processes predominantly mediating the diazotrophic community assemblage were elevation dependent. The null model based on the Jaccard similarity distance was used to test the relative influence of deterministic selections vs. stochastic processes
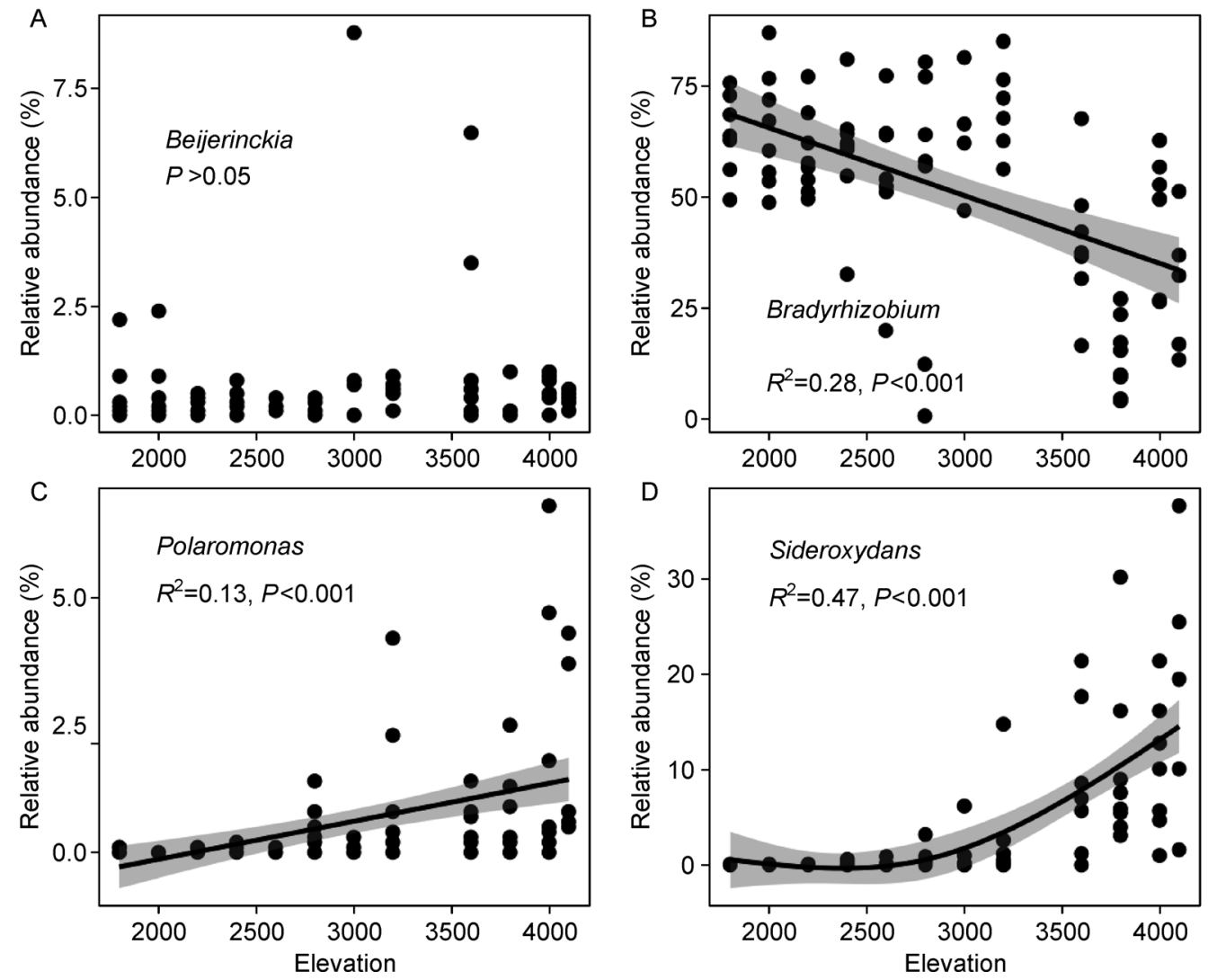

Fig. 1 Variations in the relative abundances of genus Beijerinckia (A), Bradyrhizobium (B), Polaromonas (C), and Sideroxydans (D) along the elevational gradient. A solid black symbol indicates the relative abundance in each sample at each elevation site. Lines represent best-fit regressions of their abundances versus elevations. Gray shadow represents $95 \%$ confidence interval. 

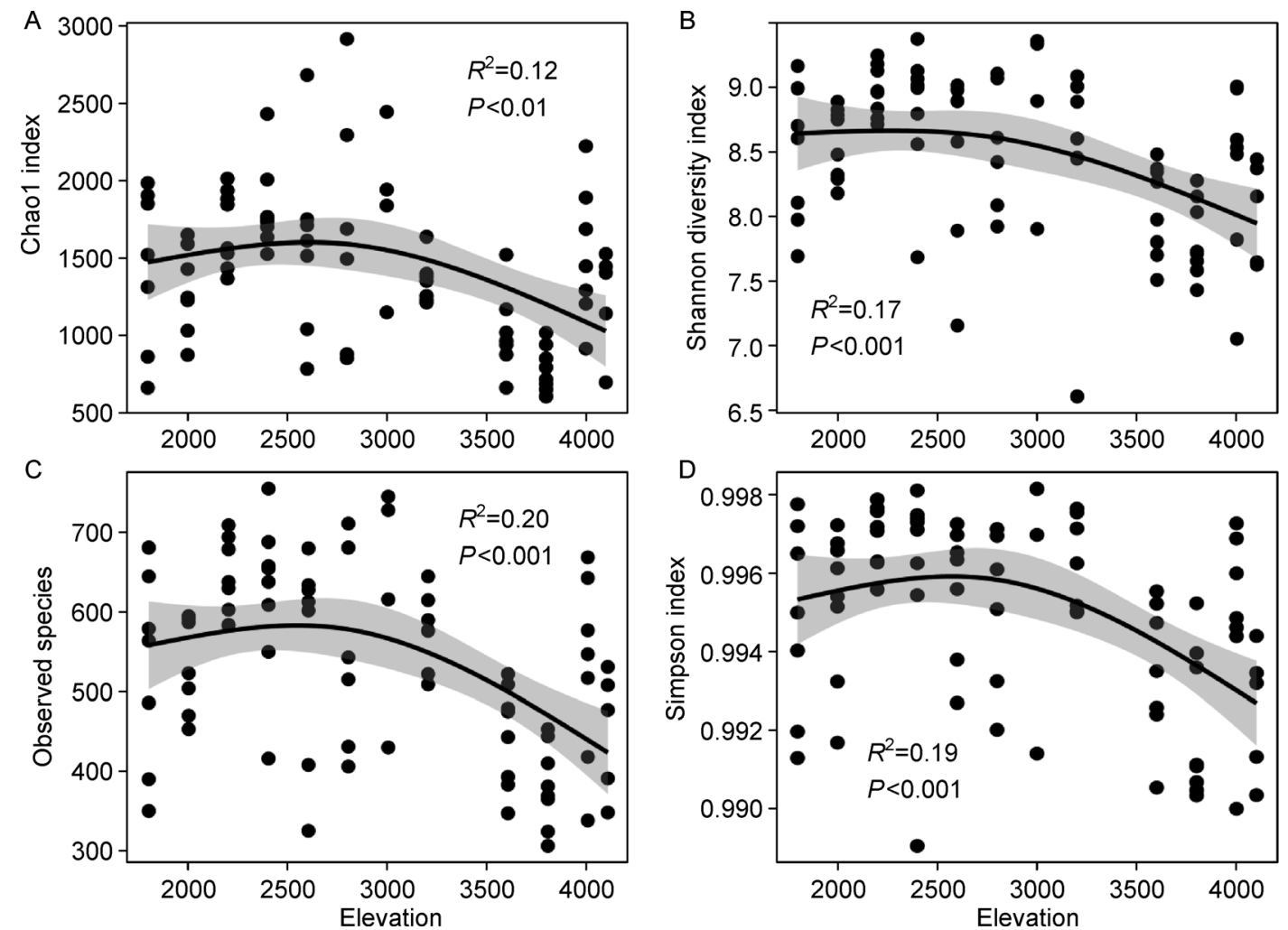

Fig. 2 Variations in Chao1 index (A), Shannon diversity index (B), Observed species (C) and Simpson index (D) of diazotrophs with elevations. Polynomial function was used to describe the relationships between diversity indices and elevations. Gray shadow represents $95 \%$ confidence interval.

Table 1 The correlations of $\alpha$-, $\beta$-diversity of diazotrophs with abiotic variables using Spearman's rho.

\begin{tabular}{|c|c|c|c|c|c|c|}
\hline & \multicolumn{2}{|l|}{ Chao1 } & \multicolumn{2}{|c|}{ Shannon } & \multicolumn{2}{|c|}{ Jaccard } \\
\hline & $R$ & $P$ & $R$ & $P$ & $R$ & $P$ \\
\hline Elevation & -0.315 & 0.004 & -0.373 & 0.000 & 0.581 & 0.001 \\
\hline MAP & -0.323 & 0.003 & -0.400 & 0.000 & 0.568 & 0.001 \\
\hline MAT & 0.322 & 0.003 & 0.398 & 0.000 & 0.568 & 0.001 \\
\hline Plant richness & 0.399 & 0.000 & 0.413 & 0.000 & 0.600 & 0.001 \\
\hline NDVI & 0.044 & 0.690 & 0.079 & 0.474 & 0.242 & 0.001 \\
\hline $\mathrm{pH}$ & 0.235 & 0.031 & 0.241 & 0.027 & 0.455 & 0.001 \\
\hline Conductivity & 0.376 & 0.000 & 0.380 & 0.000 & 0.207 & 0.001 \\
\hline $\mathrm{TN}$ & 0.416 & 0.000 & 0.456 & 0.000 & 0.230 & 0.001 \\
\hline $\mathrm{TC}$ & 0.415 & 0.000 & 0.449 & 0.000 & 0.210 & 0.001 \\
\hline $\mathrm{C} / \mathrm{N}$ & 0.220 & 0.045 & 0.218 & 0.047 & 0.176 & 0.001 \\
\hline $\mathrm{NH}_{4}{ }^{+}-\mathrm{N}$ & 0.333 & 0.002 & 0.428 & 0.000 & 0.152 & 0.001 \\
\hline $\mathrm{NO}_{3}{ }^{-}-\mathrm{N}$ & 0.307 & 0.004 & 0.311 & 0.004 & 0.143 & 0.003 \\
\hline
\end{tabular}

MAP: Mean annual precipitation; MAT: Mean annual temperature; TN: Total nitrogen; TC: Total carbon. The significances were tested based on 10000 permutations.

on the assembly of diazotrophs across the elevational gradient. The results showed that the values of observed similarity $\left(\mathrm{J}_{\mathrm{obs}}\right)$ and average expected similarity $\left(\mathrm{J}_{\exp }\right)$ had significant differences at $1800 \mathrm{~m}$ to $2200 \mathrm{~m}$ and $3200 \mathrm{~m}$ to $4100 \mathrm{~m}(P<0.01)$. Additionally, SES is an indicator measuring the deviation of $\mathrm{J}_{\mathrm{obs}}$ from $\overline{\mathrm{J}}_{\mathrm{exp}}$, representing the influence of deterministic factors on communities. The second-degree polynomial function was used to describe the relationship between SES and elevation. It showed that the median values of SES were more than +2 at $1800 \mathrm{~m}$ to $2200 \mathrm{~m}$ and $3200 \mathrm{~m}$ to $4100 \mathrm{~m}$ (Fig. $4, R^{2}=0.20, P<0.001$ ). The results indicated that deterministic processes played predominant roles gov- 

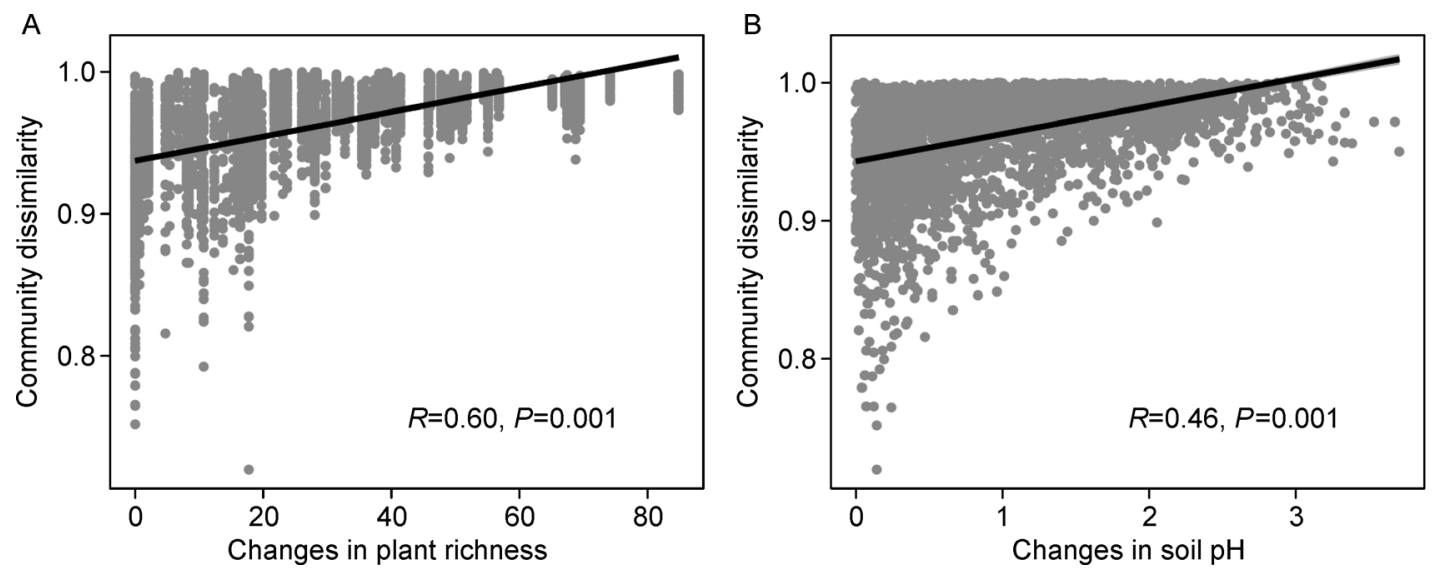

Fig. 3 Correlations between plant richness (A), pH (B), and Jaccard dissimilarity with Mantel tests using Spearman's rho.

erning diazotrophic communities at these two elevation ranges.

However, no significant differences were observed between $\mathrm{J}_{\mathrm{obs}}$ and $\overline{\mathrm{J}}_{\exp }$ at the middle elevations $(2400 \mathrm{~m}$ to $3000 \mathrm{~m}, P>0.01$, Table 2), and the median values of SES were below +2 and above -2 (Fig. 4). This implied that stochastic processes played major roles in the diazotrophic community assembly at the middle elevations. In this elevation range, conifer and broad-leaved mixed forest (CBMF; $2600 \mathrm{~m}$ to $2800 \mathrm{~m}$ ) and dark coniferous forests (DCF; $3000 \mathrm{~m}$ ) were distributed. Using the Bray-Curtis distance for the analysis above, dynamical behaviors of the two processes on diazotrophic communities changed consistently with those using the Jaccard similarity distance except at $2400 \mathrm{~m}$ and $3200 \mathrm{~m}$ (Table S8). All these results indicated that changes in selective environments along the elevational gradient could cause shifts of the relative contributions from stochastic and deterministic processes.

\section{Discussion}

4.1 Downtrend pattern of diazotrophic $\alpha$-diversity with elevation correlates with soil total $\mathrm{C}$, total $\mathrm{N}$, and plant richness

The diversity of diazotrophs at low elevations was largely distinct from those of high elevations, and the diversity dramatically decreased at elevations above $3000 \mathrm{~m}$ a.s.I. The observed diversity pattern for diazotrophs was similar to that of total bacteria in this mountain, which showed the stairstep pattern with an abrupt decrease between 2600 and 2800 $m$ a.s.l. (Li et al., 2018). A possible explanation for such a downtrend pattern in the alpha-diversity of diazotrophs is that the elevation change had a significant effect on abiotic factors that are important in shaping the diazotrophic community, including temperature, precipitation, soil properties, etc. Few species are able to tolerate an entire environmental gradient. With a relatively moderate temperature and humidity, high plant diversity at the low and middle elevations would maintain

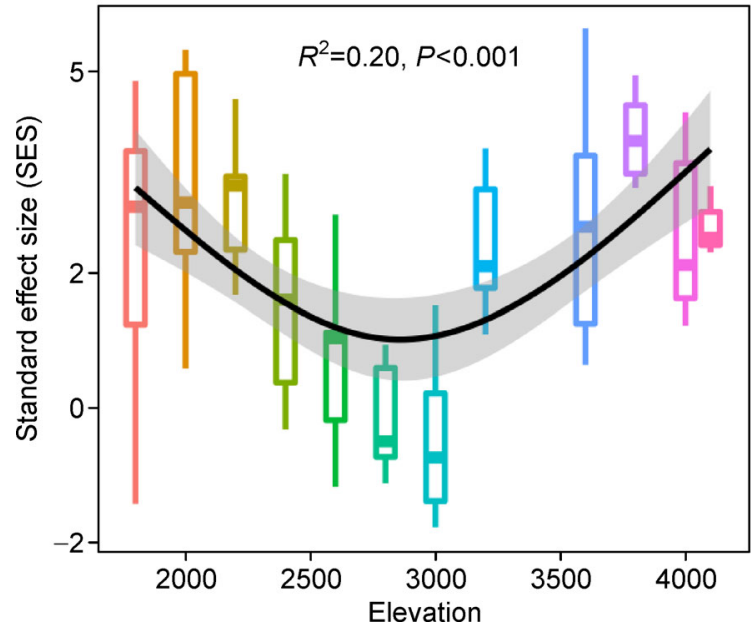

Fig. 4 Changes of standard effect size (SES) in different elevations. SES is the difference between the observed similarity and the null expected similarity divided by the SD of community similarity from null expectation, which is used to measure the influence of deterministic factors on community composition and abundance. Solid black line indicates a quadratic polynomial curve. Gray shadow represents $95 \%$ confidence interval.

a high biodiversity, while most species would be limited (e.g., Bradyrhizobium) when the environment is perennially cool and moist at a high elevation (Brown, 2001). Polaromonas and Sideroxydans, which have strategies to survive and metabolize at low temperatures, are commonly found in cryospheric and high-latitude environments (Hell et al., 2013; Achberger et al., 2017). Our results agreed in that these species had higher relative abundances at high-elevation soils (Fig. 1C and D).

The most influential factors on a-diversity were soil TC, TN, and plant richness. We found that the higher soil TC and TN contents could preserve a higher diazotrophic diversity. Soil TC or TN provides an integrative index for the soil nutrient level, which regulates microbial nitrogen and carbon use efficiencies and maintains microbial element homeostasis 
Table 2 Significance tests between centroid of $\mathrm{J}_{\mathrm{obs}}$ (observed similarity) and $\overline{\mathrm{J}}_{\text {exp }}$ (average expected similarity by chance) across elevations using PERMDISP.

\begin{tabular}{lllcl}
\hline Elevation & Centroid of $\mathrm{J}_{\text {obs }}$ & Centroid of $\mathrm{J}_{\text {exp }}$ & $F$ & \\
\hline 1800 & 0.076 & 0.037 & 9.740 & 0.003 \\
2000 & 0.095 & 0.041 & 19.211 & 0.001 \\
2200 & 0.098 & 0.049 & 41.273 & 0.001 \\
2400 & 0.071 & 0.046 & 4.996 & 0.042 \\
2600 & 0.062 & 0.039 & 3.595 & 0.060 \\
2800 & 0.075 & 0.039 & 4.907 & 0.053 \\
3000 & 0.054 & 0.041 & 2.366 & 0.165 \\
3200 & 0.094 & 0.041 & 12.371 & 0.003 \\
3600 & 0.095 & 0.033 & 19.569 & 0.001 \\
3800 & 0.137 & 0.029 & 54.288 & 0.001 \\
4000 & 0.070 & 0.038 & 19.080 & 0.001 \\
4100 & 0.082 & 0.032 & 9.369 & 0.001 \\
\hline
\end{tabular}

(Mooshammer et al., 2014). Soil nutrients also affect bacterial communities through soil acidification, supplying microelements (e.g., molybdenum) that control the soil bacterial diversity and community compositions (Wichard et al., 2009; Liu et al., 2015). This phenomenon in our study is similar to the response patterns of microbial diversity to the application of organic fertilizer, which increases microbial diversity with organic matter inputs (Tang et al., 2017; Liao et al., 2018).

Plant richness decreased from the lowest to highest elevations and followed an interrelated pattern with diazotrophs. However, some studies suggest that plant and microbial communities exhibit different patterns of diversity across elevational gradients (Bryant et al., 2008; Fierer et al., 2011). The inconsistent relationship between bacteria and plant diversity is partly caused by the absence of a large elevational gradient (e.g., $2460 \mathrm{~m}$ to $3380 \mathrm{~m}$ in Bryant et al. (2008)) or the higher spatial heterogeneity within each sampling elevation than among different elevations (Fierer et al., 2011).

Two related hypotheses were provided to interpret the congruent diversity patterns of diazotrophs and plants across the elevational gradient. First, nitrogen-fixing bacteria can enhance plant growth by directly influencing the availability of nutrients and contributing to the maintenance of plant productivity and diversity (van Der Heijden et al., 2006, 2008). Second, interrelated patterns of plants and diazotrophs may be shaped by shared environmental drivers (e.g., MAT, MAP, soil temperature, $\mathrm{pH}$, and total nitrogen). Climate is considered an important regulator for plant community composition and diversity and microbial communities (Jump and Peñuelas, 2005; Singh et al., 2010; Harrison et al., 2015). Climate may be a potential force to shape diversity patterns of both plants and diazotrophs. Nottingham et al. (2018) report that temperature plays a fundamental role in driving the coordinated patterns of plant and soil microbial diversity, based on their survey from the Amazon rainforest to the Andes Mountains. Furthermore, soil $\mathrm{pH}$, conductivity, $\mathrm{NH}_{4}{ }^{+}-\mathrm{N}$, $\mathrm{NO}_{3}{ }^{-} \mathrm{N}, \mathrm{TC}$, and $\mathrm{TN}$ were consistently correlated with both plant and diazotrophic diversity (Tables 1 and S9). High plant richness may input more abundant and diverse root exudates and leaf litter into soils to support higher diazotrophic diversity (Pan et al., 2011; Paul, 2016). These plant-driven soil characteristics may trigger the convergence of plant and diazotrophic diversity patterns.

Except for a-diversity, plant richness and elevation-associated climate factors significantly shift the assembly of diazotrophs ( $\beta$-diversity) (Fig. 3 and Tables 1, S7). Elevation-related niches resulted in changes in climate and vegetation types from the subtropical to the alpine cold vegetation from $1800 \mathrm{~m}$ to $4100 \mathrm{~m}$ in this study. These forces can structure diazotrophic communities by facilitating the growth of resistant species and limiting microbes that have a weak adaptation. Among the soil variables, soil $\mathrm{pH}$ was recognized as a major factor driving the community structure of diazotrophs along the elevational gradient because soil $\mathrm{pH}$ could impose physiological constraints on bacteria and affect nutrient availability directly or indirectly (Lauber et al., 2009; Wang et al., 2017b).

\subsection{Ecological processes determining diazotrophic community assemblage shifts along the elevational gradient}

Empirical studies have revealed that both deterministic and stochastic processes are important in the development of community assemblages, and the relative importance of assembly processes can vary with environmental gradients or disturbances (Chase, 2007b; Rominger et al., 2009; Guo et al., 2014; Vellend et al., 2014; Zhang et al., 2016). We found that stochasticity and determinacy were fluctuant along the elevational gradient for the diazotrophic community. Deterministic processes played predominant roles at low and high elevations, but their relative importance decreased at middle elevations.

First, our study showed that broad-leaved forests dominated at low elevations. With similar forest types at low elevations, stochastic processes would be weak compared to 
the dominant selection effects that would promote communities to be more niche-assembled. Human disturbance is heavy at the low elevations, which may be an additional ineluctable selection factor. Human disturbance could increase microbe mortality, slow the growth of the remaining species, decrease the connectivity between species, and ultimately result in deterministic dominance (Chase, 2010; Vellend and Agrawal, 2010; Hawkins et al., 2015).

Second, this study showed that stochastic processes were enhanced and the relative roles of deterministic processes were weakened at the middle elevations. Mixed forests of deciduous broad-leaved and coniferous species dominated at this elevation range, a factor that may increase the environmental heterogeneity. This could lead to more divergent community compositions and weaken the deterministic selection by reducing competition for resources (DiniAndreote et al., 2015). More diverse substrates (e.g., diverse litters or root exudates) may generate different free-living diazotrophs with less overlap. Meanwhile, the substrates could stimulate the growth of individual species and an idiosyncratic community assembly (Broughton et al., 2003; Badri et al., 2013). Thus, a diverse resource environment would reduce competitive pressures, increase the occurrence of rare species, and lead to the dominance of stochasticity on diazotrophic community assemblages.

Third, our results showed that stochasticity decreased at high elevations. We speculated that cold temperatures would constitute a strong filtering factor at the high elevations, which would increase the relative abundance of diazotrophic species (e.g., Polaromonas and Sideroxydans) that are adapted to cold and anoxic habitats. Besides climate factors, high-elevation areas are characterized by a low soil carbon content and significant restrictions in nutrient supplies, which may also enhance stress for diazotrophs. Hence, the harsh environmental filtering may make deterministic selection more important than stochastic forces.

Overall, our evidence demonstrated that diazotrophic community assemblages depend on a complex balance between deterministic and stochastic forces at different elevational ranges. These results provide significant insights into how ecological processes affect diazotrophic communities with constantly changing environments along an elevational gradient.

\section{Acknowledgments}

The work was supported by the National Natural Science Foundation of China $(41771293,41630751,31670503)$ and Chinese Academy of Sciences (XXH13503-03-106, XDB15010303), Open Fund of Key Laboratory of Environmental and Applied Microbiology CAS (KLCAS-2017-3, KLCAS-201603), and China Biodiversity Observation Networks (Sino BON).

\section{Electronic supplementary material}

Supplementary material is available in the online version of this article at http://dx.doi.org/10.1007/s42832-019-013-y and is accessible for authorized users.

\section{References}

Achberger, A.M., Michaud, A.B., Vick-Majors, T.J., Christner, B.C., Skidmore, M.L., Priscu, J.C., Tranter, M., 2017. Microbiology of subglacial environments, Psychrophiles: From Biodiversity to Biotechnology. Springer, pp. 83-110.

Badri, D.V., Chaparro, J.M., Zhang, R., Shen, Q., Vivanco, J.M., 2013. Application of natural blends of phytochemicals derived from the root exudates of Arabidopsis to the soil reveal that phenolic-related compounds predominantly modulate the soil microbiome. Journal of Biological Chemistry 288, 4502-4512.

Blaško, R., Bach, L.H., Yarwood, S.A., Trumbore, S.E., Högberg, P., Högberg, M.N., 2015. Shifts in soil microbial community structure, nitrogen cycling and the concomitant declining $\mathrm{N}$ availability in ageing primary boreal forest ecosystems. Soil Biology \& Biochemistry $91,200-211$.

Broughton, W.J., Zhang, F., Perret, X., Staehelin, C., 2003. Signals exchanged between legumes and Rhizobium: agricultural uses and perspectives. Plant and Soil 252, 129-137.

Brown, J.H., 2001. Mammals on mountainsides: Elevational patterns of diversity. Global Ecology and Biogeography 10, 101-109.

Bryant, J.A., Lamanna, C., Morlon, H., Kerkhoff, A.J., Enquist, B.J., Green, J.L., 2008. Colloquium paper: microbes on mountainsides: contrasting elevational patterns of bacterial and plant diversity. Proceedings of the National Academy of Sciences of the United States of America 105, 11505-11511.

Chao, A., 1984. Nonparametric estimation of the number of classes in a population. Scandinavian Journal of Statistics 11, 265-270.

Chase, J.M., 2007a. Drought mediates the importance of stochastic community assembly. Proceedings of the National Academy of Sciences of the United States of America 104, 17430-17434.

Chase, J.M., 2007b. Drought mediates the importance of stochastic community assembly. Proceedings of the National Academy of Sciences of the United States of America 104, 17430-17434.

Chase, J.M., 2010. Stochastic community assembly causes higher biodiversity in more productive environments. Science 328, 13881391.

Chase, J.M., Myers, J.A., 2011. Disentangling the importance of ecological niches from stochastic processes across scales. Philosophical Transactions of the Royal Society of London. Series B, Biological Sciences 366, 2351-2363.

Cheng, G., Luo, J., 2003. The carbon accumulation and dissipation features of sub-alpine woodland in Mt. Gongga. Journal of Geographical Sciences 13, 13-18.

Clarke, K.R., 1993. Non-parametric multivariate analyses of changes in community structure. Austral Ecology 18, 117-143.

Collavino, M.M., Tripp, H.J., Frank, I.E., Vidoz, M.L., Calderoli, P.A., Donato, M., Zehr, J.P., Aguilar, O.M., 2014. nifH pyrosequencing reveals the potential for location-specific soil chemistry to influence $\mathrm{N}_{2}$-fixing community dynamics. Environmental Microbiology 16 , 3211-3223.

DeLuca, T.H., Zackrisson, O., Nilsson, M.C., Sellstedt, A., 2002. 
Quantifying nitrogen-fixation in feather moss carpets of boreal forests. Nature 419, 917-920.

Desgarennes, D., Garrido, E., Torres-Gomez, M.J., Peña-Cabriales, J.J., Partida-Martinez, L.P., 2014. Diazotrophic potential among bacterial communities associated with wild and cultivated Agave species. FEMS Microbiology Ecology 90, 844-857.

Dini-Andreote, F., Stegen, J.C., van Elsas, J.D., Salles, J.F., 2015. Disentangling mechanisms that mediate the balance between stochastic and deterministic processes in microbial succession. Proceedings of the National Academy of Sciences of the United States of America 112, E1326-E1332.

Doane, T.A., Horwáth, W.R., 2003. Spectrophotometric determination of nitrate with a single reagent. Analytical Letters 36, 2713-2722.

Dumbrell, A.J., Nelson, M., Helgason, T., Dytham, C., Fitter, A.H., 2010. Relative roles of niche and neutral processes in structuring a soil microbial community. ISME Journal 4, 337-345.

Elsen, P.R., Tingley, M.W., 2015. Global mountain topography and the fate of montane species under climate change. Nature Climate Change 5, 772-776.

Farnelid, H., Bentzon-Tilia, M., Andersson, A.F., Bertilsson, S., Jost, G., Labrenz, M., Jürgens, K., Riemann, L., 2013. Active nitrogenfixing heterotrophic bacteria at and below the chemocline of the central Baltic Sea. ISME Journal 7, 1413-1423.

Fierer, N., McCain, C.M., Meir, P., Zimmermann, M., Rapp, J.M., Silman, M.R., Knight, R., 2011. Microbes do not follow the elevational diversity patterns of plants and animals. Ecology 92, 797-804.

Gower, J.C., 1966. Some distance properties of latent root and vector methods used in multivariate analysis. Biometrika 53, 325-338.

Guo, H., Więski, K., Lan, Z., Pennings, S.C., 2014. Relative influence of deterministic processes on structuring marsh plant communities varies across an abiotic gradient. Oikos 123, 173-178.

Harrison, S.P., Gornish, E.S., Copeland, S., 2015. Climate-driven diversity loss in a grassland community. Proceedings of the National Academy of Sciences of the United States of America 112, 8672-8677.

Hawkins, C.P., Mykrä, H., Oksanen, J., Vander Laan, J.J., 2015. Environmental disturbance can increase beta diversity of stream macroinvertebrate assemblages. Global Ecology and Biogeography 24, 483-494.

Hell, K., Edwards, A., Zarsky, J., Podmirseg, S.M., Girdwood, S., Pachebat, J.A., Insam, H., Sattler, B., 2013. The dynamic bacterial communities of a melting High Arctic glacier snowpack. ISME Journal 7, 1814-1826.

Huson, D.H., Auch, A.F., Qi, J., Schuster, S.C., 2007. MEGAN analysis of metagenomic data. Genome Research 17, 377-386.

Jump, A.S., Peñuelas, J., 2005. Running to stand still: Adaptation and the response of plants to rapid climate change. Ecology Letters 8 , 1010-1020.

Lauber, C.L., Hamady, M., Knight, R., Fierer, N., 2009. Pyrosequencing-based assessment of soil $\mathrm{pH}$ as a predictor of soil bacterial community structure at the continental scale. Applied and Environmental Microbiology 75, 5111-5120.

Leibold, M.A., McPeek, M.A., 2006. Coexistence of the niche and neutral perspectives in community ecology. Ecology 87, 13991410.
Li, J., Shen, Z., Li, C., Kou, Y., Wang, Y., Tu, B., Zhang, S., Li, X., 2018. Stair-step pattern of soil bacterial diversity mainly driven by $\mathrm{pH}$ and vegetation types along the elevational gradients of Gongga Mountain, China. Frontiers in Microbiology 9, 569.

Li, W., Yang, G., Chen, H., Tian, J., Zhang, Y., Zhu, Q.A., Peng, C., Yang, J.A., 2013. Soil available nitrogen, dissolved organic carbon and microbial biomass content along altitudinal gradient of the eastern slope of Gongga Mountain. Acta Ecologica Sinica 33, 266-271.

Liao, H., Li, Y., Yao, H., 2018. Fertilization with inorganic and organic nutrients changes diazotroph community composition and $\mathrm{N}$ fixation rates. Journal of Soils and Sediments 18, 1076-1086.

Liu, J., Sui, Y., Yu, Z., Shi, Y., Chu, H., Jin, J., Liu, X., Wang, G., 2015. Soil carbon content drives the biogeographical distribution of fungal communities in the black soil zone of northeast China. Soil Biology \& Biochemistry 83, 29-39.

Lu, X., Cheng, G., 2009. Climate change effects on soil carbon dynamics and greenhouse gas emissions in Abies fabri forest of subalpine, southwest China. Soil Biology \& Biochemistry 41, 1015-1021.

McCain, C.M., 2005. Elevational gradients in diversity of small mammals. Ecology 86, 366-372.

Mooshammer, M., Wanek, W., Hämmerle, I., Fuchslueger, L., Hofhansl, F., Knoltsch, A., Schnecker, J., Takriti, M., Watzka, M., Wild, B., Keiblinger, K.M., Zechmeister-Boltenstern, S., Richter, A., 2014. Adjustment of microbial nitrogen use efficiency to carbon: nitrogen imbalances regulates soil nitrogen cycling. Nature Communications 5, 3694.

Myers, J.A., Chase, J.M., Jiménez, I., Jørgensen, P.M., AraujoMurakami, A., Paniagua-Zambrana, N., Seidel, R., 2013. Betadiversity in temperate and tropical forests reflects dissimilar mechanisms of community assembly. Ecology Letters 16, 151157.

Nottingham, A.T., Fierer, N., Turner, B.L., Whitaker, J., Ostle, N.J., McNamara, N.P., Bardgett, R.D., Leff, J.W., Salinas, N., Silman, M. R., Kruuk, L.E.B., Meir, P., 2018. Microbes follow Humboldt: temperature drives plant and soil microbial diversity patterns from the Amazon to the Andes. Ecology 99, 2455-2466.

Oksanen, J., Kindt, R., Legendre, P., O'Hara, B., Stevens, M.H.H., Oksanen, M.J., Suggests, M., 2007. The vegan package. Community Ecology Package 10, 631-637.

Pan, Y., Birdsey, R.A., Fang, J., Houghton, R., Kauppi, P.E., Kurz, W. A., Phillips, O.L., Shvidenko, A., Lewis, S.L., Canadell, J.G., Ciais, P., Jackson, R.B., Pacala, S.W., McGuire, A.D., Piao, S., Rautiainen, A., Sitch, S., Hayes, D., 2011. A large and persistent carbon sink in the world's forests. Science 333, 988-993.

Paradis, E., Claude, J., Strimmer, K., 2004. APE: analyses of phylogenetics and evolution in $\mathrm{R}$ language. Bioinformatics (Oxford, England) 20, 289-290.

Paul, E.A., 2016. The nature and dynamics of soil organic matter: Plant inputs, microbial transformations, and organic matter stabilization. Soil Biology \& Biochemistry 98, 109-126.

Pettorelli, N., Gaillard, J.M., Mysterud, A., Duncan, P., Delorme, D., Van Laere, G., Toïgo, C., Klein, F., 2006. Using a proxy of plant productivity (NDVI) to find key periods for animal performance: The case of roe deer. Oikos 112, 565-572. 
Piao, S., Nan, H., Huntingford, C., Ciais, P., Friedlingstein, P., Sitch S., Peng, S., Ahlström, A., Canadell, J.G., Cong, N., Levis, S., Levy, P.E., Liu, L., Lomas, M.R., Mao, J., Myneni, R.B., Peylin, P., Poulter, B., Shi, X., Yin, G., Viovy, N., Wang, T., Wang, X., Zaehle, S., Zeng, N., Zeng, Z., Chen, A., 2014. Evidence for a weakening relationship between interannual temperature variability and northern vegetation activity. Nature Communications 5, 5018.

Poly, F., Monrozier, L.J., Bally, R., 2001. Improvement in the RFLP procedure for studying the diversity of nifH genes in communities of nitrogen fixers in soil. Research in Microbiology 152, 95-103.

Rahbek, C., 1995. The elevational gradient of species richness: A uniform pattern? Ecography 18, 200-205.

Rastetter, E.B., Vitousek, P.M., Field, C., Shaver, G.R., Herbert, D., Gren, G.I., 2001. Resource optimization and symbiotic nitrogen fixation. Ecosystems (New York, N.Y.) 4, 369-388.

Reed, S.C., Cleveland, C.C., Townsend, A.R., 2011. Functional ecology of free-living nitrogen fixation: A contemporary perspective. Annual Review of Ecology Evolution and Systematics 42, 489-512.

Reed, S.C., Cleveland, C.C., Townsend, A.R., 2013. Relationships among phosphorus, molybdenum and free-living nitrogen fixation in tropical rain forests: Results from observational and experimental analyses. Biogeochemistry 114, 135-147.

Rominger, A.J., Miller, T.E., Collins, S.L., 2009. Relative contributions of neutral and niche-based processes to the structure of a desert grassland grasshopper community. Oecologia 161, 791-800.

Rowe, R.J., Heaney, L.R., Rickart, E.A., 2015. Scale effects on the pattern and predictors of small mammal diversity along a local elevational gradient in the Great Basin. Journal of Biogeography 42, 1964-1974.

Rui, J., Li, J., Wang, S., An, J., Liu, W.T., Lin, Q., Yang, Y., He, Z., Li, X., 2015. Responses of bacterial communities to simulated climate changes in alpine meadow soil of the Qinghai-Tibet Plateau. Applied and Environmental Microbiology 81, 6070-6077.

Santos, H.F., Carmo, F.L., Duarte, G., Dini-Andreote, F., Castro, C.B., Rosado, A.S., van Elsas, J.D., Peixoto, R.S., 2014. Climate change affects key nitrogen-fixing bacterial populations on coral reefs. ISME Journal 8, 2272-2279.

Shannon, C.E., Weaver, W., Burks, A.W., 1951. The mathematical theory of communication $60,3$.

Shen, C., Liang, W., Shi, Y., Lin, X., Zhang, H., Wu, X., Xie, G., Chain, P., Grogan, P., Chu, H., 2014. Contrasting elevational diversity patterns between eukaryotic soil microbes and plants. Ecology 95, 3190-3202.

Shen, C., Xiong, J., Zhang, H., Feng, Y., Lin, X., Li, X., Liang, W., Chu, $\mathrm{H}$., 2013. Soil $\mathrm{pH}$ drives the spatial distribution of bacterial communities along elevation on Changbai Mountain. Soil Biology \& Biochemistry $57,204-211$

Shen, Z., Fang, J., Liu, Z., Wu, J., 2001. Patterns of biodiversity along the vertical vegetation spectrum of the east aspect of Gongga Mountain. Acta Phytoecologica Sinica 25, 721-732.

Simpson, E.H., 1949. Measurement of diversity. Nature163-688.

Singh, B.K., Bardgett, R.D., Smith, P., Reay, D.S., 2010. Microorganisms and climate change: terrestrial feedbacks and mitigation options. Nature Reviews. Microbiology 8, 779-790.

Smith, M.A., Hallwachs, W., Janzen, D.H., 2014. Diversity and phylogenetic community structure of ants along a Costa Rican elevational gradient. Ecography 37, 720-731.

Sproull, G.J., Quigley, M.F., Sher, A., González, E., 2015. Long-term changes in composition, diversity and distribution patterns in four herbaceous plant communities along an elevational gradient. Journal of Vegetation Science 26, 552-563.

Sun, H., Wu, Y., Zhou, J., Bing, H., 2016. Variations of bacterial and fungal communities along a primary successional chronosequence in the Hailuogou glacier retreat area (Gongga Mountain, SW China). Journal of Mountain Science 13, 1621-1631.

Tang, Y., Zhang, M., Chen, A., Zhang, W., Wei, W., Sheng, R., 2017. Impact of fertilization regimes on diazotroph community compositions and $\mathrm{N}_{2}$-fixation activity in paddy soil. Agriculture, Ecosystems \& Environment 247, 1-8.

Thébault, A., Clément, J.C., Ibanez, S., Roy, J., Geremia, R.A., Pérez, C.A., Buttler, A., Estienne, Y., Lavorel, S., 2014. Nitrogen limitation and microbial diversity at the treeline. Oikos 123, 729-740.

Tian, J., Wu, B., Chen, H., Jiang, N., Kang, X., Liu, X., 2017. Patterns and drivers of fungal diversity along an altitudinal gradient on Mount Gongga, China. Journal of Soils and Sediments 17, 1-10.

Tilman, D., 2004. Niche tradeoffs, neutrality, and community structure: a stochastic theory of resource competition, invasion, and community assembly. Proceedings of the National Academy of Sciences of the United States of America 101, 10854-10861.

van der Heijden, M.G., Bardgett, R.D., van Straalen, N.M., 2008. The unseen majority: soil microbes as drivers of plant diversity and productivity in terrestrial ecosystems. Ecology Letters 11, 296310.

van der Heijden, M.G.A., Bakker, R., Verwaal, J., Scheublin, T.R., Rutten, M., van Logtestijn, R., Staehelin, C., 2006. Symbiotic bacteria as a determinant of plant community structure and plant productivity in dune grassland. FEMS Microbiology Ecology 56, 178-187.

Vellend, M., Agrawal, A., 2010. Conceptual synthesis in community ecology. Quarterly Review of Biology 85, 183-206.

Vellend, M., Srivastava, D.S., Anderson, K.M., Brown, C.D., Jankowski, J.E., Kleynhans, E.J., Kraft, N.J., Letaw, A.D., Macdonald, A.A.M., Maclean, J.E., Myers-Smith, I.H., Norris, A. R., Xue, X., 2014. Assessing the relative importance of neutral stochasticity in ecological communities. Oikos 123, 1420-1430.

Vitousek, P.M., Howarth, R.W., 1991. Nitrogen limitation on land and in the sea: How can it occur? Biogeochemistry 13, 87-115.

Wang, D., Xu, A., Elmerich, C., Ma, L.Z., 2017a. Biofilm formation enables free-living nitrogen-fixing rhizobacteria to fix nitrogen under aerobic conditions. ISME Journal 11, 1602-1613.

Wang, L., Ouyang, H., Zhou, C.P., Zhang, F., Song, M.H., Tian, Y.Q., 2005. Soil organic matter dynamics along a vertical vegetation gradient in the Gongga Mountain on the Tibetan Plateau. Journal of Integrative Plant Biology 47, 411-420.

Wang, Y., Li, C., Kou, Y., Wang, J., Tu, B., Li, H., Li, X., Wang, C., Yao, M., 2017b. Soil pH is a major driver of soil diazotrophic community assembly in Qinghai-Tibet alpine meadows. Soil Biology \& Biochemistry 115, 547-555.

Wartiainen, I., Eriksson, T., Zheng, W., Rasmussen, U., 2008. Variation in the active diazotrophic community in rice paddy - nifH PCR-DGGE analysis of rhizosphere and bulk soil. Applied Soil 
Ecology 39, 65-75.

Weatherburn, M., 1967. Phenol-hypochlorite reaction for determination of ammonia. Analytical Chemistry 39, 971-974.

Wichard, T., Mishra, B., Myneni, S.C., Bellenger, J.P., Kraepiel, A.M., 2009. Storage and bioavailability of molybdenum in soils increased by organic matter complexation. Nature Geoscience 2, 625-629.

Wu, Y., Colwell, R.K., Rahbek, C., Zhang, C., Quan, Q., Wang, C., Lei, F., 2013a. Explaining the species richness of birds along a subtropical elevational gradient in the Hengduan Mountains. Journal of Biogeography 40, 2310-2323.

Wu, Y., Yang, Q., Wen, Z., Xia, L., Zhang, Q., Zhou, H., 2013b. What drives the species richness patterns of non-volant small mammals along a subtropical elevational gradient? Ecography 36, 185-196.
Zehr, J.P., Jenkins, B.D., Short, S.M., Steward, G.F., 2003. Nitrogenase gene diversity and microbial community structure: a crosssystem comparison. Environmental Microbiology 5, 539-554.

Zhang, X., Johnston, E.R., Liu, W., Li, L., Han, X., 2016. Environmental changes affect the assembly of soil bacterial community primarily by mediating stochastic processes. Global Change Biology 22, 198-207.

Zhou, J., Deng, Y., Zhang, P., Xue, K., Liang, Y., Van Nostrand, J.D., Yang, Y., He, Z., Wu, L., Stahl, D.A., Hazen, T.C., Tiedje, J.M., Arkin, A.P., 2014. Stochasticity, succession, and environmental perturbations in a fluidic ecosystem. Proceedings of the National Academy of Sciences of the United States of America 111, E836E845. 